\title{
Effectiveness of Groundwater Boiling as Household Water Treatment in Metro and Bekasi Cities, Indonesia
}

\author{
Rioneli Ghaudenson ${ }^{1}$, Cindy Rianti Priadi ${ }^{1,2 *}$ and Tim Foster $^{3}$ \\ ${ }^{1}$ Faculty of Engineering, Civil and Environmental Engineering Department, Universitas Indonesia, \\ Depok, 16424, Indonesia \\ ${ }^{2}$ Center for Sustainable Infrastructure Development, Universitas Indonesia, Depok, 16424, Indonesia \\ ${ }^{3}$ Institute for Sustainable Futures, University of Technology Sydney, Ultimo, NSW 2007, Australia
}

\begin{abstract}
Groundwater serves as a major drinking water source due to inadequate piped supplies in Indonesia. To eliminate the health risks associated with groundwater consumption, boiling appears as the most suitable and cost-effective treatment technique and widely practiced in Indonesia. Despite treatment efforts, inappropriate water storage and handling practices pose a higher risk of recontamination after treatment. The objective of this study was to analyse the effectiveness of groundwater boiling and treated water recontamination in Metro and Bekasi cities, Indonesia. Groundwater at the source and point of use samples were surveyed and assessed from a total of 116 households, resulting in $60 \%$ and $35 \%$ E. coli contamination, respectively. Paired testing involving boiling observed a reduction in microbial risk for $45 \%$ of households. However, $12 \%$ samples had an increase in risk even though boiling was reported. Furthermore, E. coli concentration at source prior to boiling and point of use after boiling showed a statistically significant difference $(\mathrm{N}=111, \mathrm{P}<0.01)$. This study demonstrated the effectiveness of boiling in reducing contamination, although recontamination was evident in some cases, likely due to unsafe water storage and unhygienic environment.
\end{abstract}

\section{Introduction}

The World Health Organization (WHO) defines a safe drinking water source as one without any significant health risk [1]. In addition, access to safe consumption is also contained in the Sustainable Development Goals (SDGs). This global initiative considers availability of water that is free from faecal contamination as an important national objective for developing countries, specifically Indonesia [2]. Based on the 2018 National Socio-Economic Survey by Badan Pusat Statistik (BPS), the percentage of families with available improved water sources remained $72.04 \%$. Also, no particular province obtained was rated $100 \%$ [3]. There is a consistent national shortage in a piped distribution system. In 2020, service coverage persisted at $20.29 \%$ [4]. This situation reportedly generated a

\footnotetext{
* Corresponding author: crpriadi@ui.ac.id
} 
negative stigma in certain communities, in terms of non-continuous supply, yellow coloration and mud sediment content [5]. As a consequence, most households tend to improvise with other alternatives, including groundwater, refill and bottled sources. Also, the use of self-supply measures in the form of dug wells and boreholes appears widespread, without any government support. These options are mainly preferred by low to middle income families due to affordable technology and simpler operation [6].

Unfortunately, groundwater in Indonesia demonstrates a high contamination risk from solid waste, animal excretion, and polluted environment [7]. A previous study in Lampung Selatan reported 28 out of 40 dug wells were polluted with $E$. coli at a concentration above $50 \mathrm{MPN} / 100 \mathrm{ml}$ [8], while a study in Bekasi detected $E$. coli with more than $10 \mathrm{MPN} / 100$ $\mathrm{ml}$ in $60 \%$ of dug wells and boreholes $(\mathrm{N}=254)$ [9]. Therefore, to counter this negative effect, boiling is extensively applied, with government support over the past decades. Furthermore, research in Guatemala showed an E. coli reduction by $13.7 \log _{10}$ using the boiling method [10], while in South Sulawesi, Indonesia, a lower E. coli count $(0.8$ MPN/100 ml, N=204) was obtained in the boiled water, compared to untreated grades (29.9 MPN/100 ml, N=36) [11]. However, improper boiling is not able to completely eliminate the pathogens [12].

Apart from water source, recontamination possibly occurs after treatment, due to inadequate storage [13]. A systematic review of 310 water quality studies found that stored water was more likely to be contaminated than water at the source [14]. In Indonesia, studies that investigates the effectiveness of boiling in peri-urban settings and the influencing factors that contributes to recontamination events are still lacking. This study is conducted to assess microbiological effectiveness of boiling as a domestically preferred treatment method while analysing the influencing factors of water quality change from the source to point of use.

\section{Materials and Methods}

\subsection{Study setting}

This study was conducted over a 4-week period in two cities, Bekasi and Metro, between February-March and October-November, 2020, respectively. Households in Bekasi and Metro cities have a limited coverage of piped water connection. Consequently, both regions have a high use of groundwater as a water source. Three peri-urban districts in Bekasi, including Jatiluhur, Sumur Batu, and Jatirangga were chosen, while five districts were selected in Metro. These locations were preferred due to high poverty rate, high population density, reliance on groundwater, and limited access to piped utility supply. The total number of households surveyed in this study was 563, but point of use water sampling was only done in 176 households. Of those 176 households, only 116 uses groundwater as a drinking water source, with 51 situated in Bekasi and 65 in Metro. The focus of this study covers households using groundwater and boiling as a primary water treatment method.

\subsection{Household Data collection}

An online questionnaire was developed with Qualtrics, using information on water source, storage and treatment practices. The survey was composed in English and translated to Bahasa Indonesia. Local interviewers from Bekasi and Metro were adequately trained and equipped with sufficient resources for water sampling such as Whirl-Pak ${ }^{\circledR}$ sample bags, thermometer, and cooler box. In Metro city, strict health protocols were observed, due to COVID-19 pandemic. 


\subsection{Water sample collection and analysis}

Samples were obtained from a primary water source (kitchen tap) and point of use (waterfilled glass), after the field survey. In addition, alternative supplies such as from bathroom tap, yard tap, or directly from the well (if no tap were available) were also considered. A Whirl-Pak ${ }^{\circledR}$ bag was used to store $100 \mathrm{ml}$ of each sample and subsequently placed in a cooler sack at a temperature of $\leq 4^{\circ} \mathrm{C}$ to be delivered to field laboratory within 6 hours.

Furthermore analysis involved the use of IDEXX Colilert-18 ${ }^{\circledR}$ test, comprising quanti-tray of 48 small and 49 large wells, with $100 \mathrm{ml}$ reagent. These plates were then incubated for 18-22 hours, followed by the evaluation of total coliform (TC), using the number of stained wells. Subsequently, the trays were placed under a UV lamp to quantify the fluorescent wells, and determine the $E$. coli count in most probable number (MPN)/100 ml, ranging between $<1$ to $2420 / 100 \mathrm{ml}$. Therefore, to prevent external contamination, laboratory and field blanks, as well as other duplicates were assessed on a daily basis.

\subsection{Data analysis}

The questionnaire and laboratory data were analysed using Microsoft Excel and STATA IC 16.1 (StataCorp LP, College Station, TX, USA). Also, $\log _{10}$ was applied to transform $E$. coli MPN count, while $<1$ MPN was converted to 0.5 , in order to account for left-censored data. Water quality analysis involved the use of binary variable to indicate the presence or absence of microbes. Moreover, log reduction from source to point of use samples was calculated from the mean difference between the respective $E$. coli MPN counts. As a result of abnormal data distribution, non-parametric assessment was employed in this research. Furthermore, Wilcoxon signed-rank test was used to evaluate E. coli count variation, prior and after boiling. Meanwhile, the correlation between water storage and E. coli contamination was achieved with Spearman model. Paired sample analysis incorporated the use of a graph to represent the percentage change between each risk category.

\section{Results and Discussion}

\subsection{Respondent characteristics}

Table 1 outlines the overall respondent characteristics data. The majority of households in Bekasi and Metro employed boreholes (54\%) as a primary drinking water source, followed by unprotected dug wells $(41 \%)$ and protected dug wells $(4 \%)$. At the source, $60 \%$ of source samples were contaminated with $E$. coli, while at the point of use, $35 \%$ contamination was observed. Unprotected wells had the largest percentage of contamination at the point of use with $44 \%$ samples contaminated.

About $96 \%$ of households in both cities employed boiling as a primary treatment method. Meanwhile, $3 \%$ do not treat their water at all under the assumption that they are already safe to drink without treatment. The samples from these households were found to be $25 \%$ contaminated. Conversely, for residents using boiling method to treat the groundwater $(\mathrm{N}=111), 36 \%$ were found to be contaminated. This result suggests boiling was not sufficient to completely eliminate the pathogens, due to improper boiling practices [12].

Bekasi and Metro households use a wide variety of water containers, although the most common is a jug (41\%). However, 19 out of 47 (40\%) samples from jugs were 
contaminated, other vessels had a moderate concentrations of E. coli ranged from $29-$ $100 \%$. The proportion of respondents who reported using closed water containers was $97 \%$, but $E$. coli was detected in $36 \%$ of these. In contrast, open vessels were without pathogens, probably due to minimal sample size $(\mathrm{N}=3)$ needed for a robust analysis. Furthermore, the most common storage duration was estimated between 1-5 days (51\%) and the least contaminated sources had storage times of $<1$ day, implying an immediate consumption after treatment or collection. This report showed consistent results with previous finding, where prolonged stagnation provided sufficient period for E. coli regrowth [15].

Table 1. Groundwater user characteristics $(\mathrm{N}=116)$.

\begin{tabular}{|c|c|c|c|}
\hline & \multirow{2}{*}{$\frac{\text { Total samples }}{\mathrm{N}}$} & \multicolumn{2}{|c|}{ Contaminated } \\
\hline & & $\mathbf{N}$ & $\%$ \\
\hline \multicolumn{4}{|l|}{ Water source } \\
\hline Borehole & 63 & 19 & $30 \%$ \\
\hline Protected dug well & 5 & 1 & $20 \%$ \\
\hline Unprotected dug well & 48 & 21 & $44 \%$ \\
\hline \multicolumn{4}{|l|}{ Treatment method } \\
\hline Boiling & 111 & 40 & $36 \%$ \\
\hline Chlorination & 1 & 1 & $100 \%$ \\
\hline Not treated & 4 & 1 & $25 \%$ \\
\hline \multicolumn{4}{|l|}{ Water container } \\
\hline Bottle & 6 & 2 & $33 \%$ \\
\hline Bucket & 8 & 3 & $38 \%$ \\
\hline Gallon/dispenser & 12 & 5 & $42 \%$ \\
\hline Jug & 47 & 19 & $40 \%$ \\
\hline Barrel & 1 & 1 & $100 \%$ \\
\hline Kettle & 35 & 10 & $29 \%$ \\
\hline Pot & 7 & 2 & $29 \%$ \\
\hline \multicolumn{4}{|l|}{ Water container lid } \\
\hline Closed & 113 & 41 & $36 \%$ \\
\hline Not closed & 3 & 0 & $0 \%$ \\
\hline \multicolumn{4}{|l|}{ Water storage duration } \\
\hline 0 day & 54 & 18 & $33 \%$ \\
\hline $1-5$ days & 59 & 22 & $37 \%$ \\
\hline$>7$ days & 2 & 1 & $50 \%$ \\
\hline Don’t know & 1 & 0 & $0 \%$ \\
\hline
\end{tabular}

\subsection{Boiling effectiveness}

Among 116 households using groundwater source, 111 employed boiling as the main treatment method. Paired water samples were analysed, in a bid to determine the water quality change and log reduction of $E$. coli concentration. The geometric mean of point of use E. coli count in Metro was estimated as $1.48 \mathrm{MPN} / 100 \mathrm{ml}$ (95\% CI: $1.00-2.20)$ and Bekasi at $0.86 \mathrm{MPN} / 100 \mathrm{ml}(95 \% \mathrm{CI}: 0.58-1.29)$. The log reduction associated with boiling in Bekasi $\left(0.75 \pm 0.37 \log _{10}\right)$ was greater than in Metro $\left(0.38 \pm 0.34 \log _{10}\right)$, but with overall estimate of $0.53 \log _{10}(95 \%$ CI: $0.29-0.79)$ or a reduction of $70,5 \%$ across both cities. This value of reduction is less than previous studies in Guatemala (82,2\%), Vietnam (96\%), and India $(99 \%)[10,16]$, indicating an inadequate boiling practice in both cities. Furthermore, 
Wilcoxon signed-rank test was used to analyse the variation of E. coli concentration between normal and boiled paired samples, with $95 \%$ confidence level. In both locations there was a significant difference in E. Coli concentration $(\mathrm{P}<0.01$ in Bekasi, $\mathrm{P}=0.04$ in Metro, and $\mathrm{P}<0.01$ for both).

\subsection{Water quality change}

The water quality in the source and point of use samples was quantified by microbial risk, based on 2011 WHO Drinking Water Guidelines. The microbial (E. coli) risk was categorized into four levels, termed low $(<1 \mathrm{MPN} / 100 \mathrm{ml})$, medium $(1-10 \mathrm{MPN} / 100 \mathrm{ml})$, high (11-100 MPN/100 ml) and very high (>100 MPN/100 ml). This category was defined by the percentage of samples with varying risk levels from source to point of use.

Figure 1 represents the results of $40.5 \%$ low, $24.1 \%$ medium, $13.8 \%$ high and $21.6 \%$ very high risks in the source samples prior to treatment. Meanwhile, for point of use, $64.7 \%$ low, $21.6 \%$ medium, $7.8 \%$ high risk and $6.0 \%$ very high risks, were obtained. Overall, point of use samples achieved a safer condition with extensive low risk category, compared to source components ( $64.7 \%$ vs $40.5 \%$ ).

Consequently, out of the source samples, $46 \%$ obtained a decreased risk, $43 \%$ showed no change, and $11 \%$ had deteriorated risk. Samples that had deteriorated risk suggests a recontamination or regrowth of $E$. coli between treatment and the time of sampling. Previous studies also showed a significantly deterioration in water quality after collection, due to dirty vessels [17,18] or unhygienic practices among residents [16]. Based on improved risk samples, $52 \%$ of very high risk sources were adjusted to a low category, indicating a minimum $\log$ reduction of 2 . This was in accordance with previous studies, where boiled drinking water obtained a lower contamination, compared to the source samples $[10,11,16]$.

The analysis of households with deteriorating water quality between source and point of use revealed a considerable shift from low to very high risk among 2 households. These households reported boiling the water prior to drinking with a close-lid jug as a container that were stored for less than a day. The finding also suggested a sudden recontamination, due to other factor(s), apart from water treatment and storage practices.

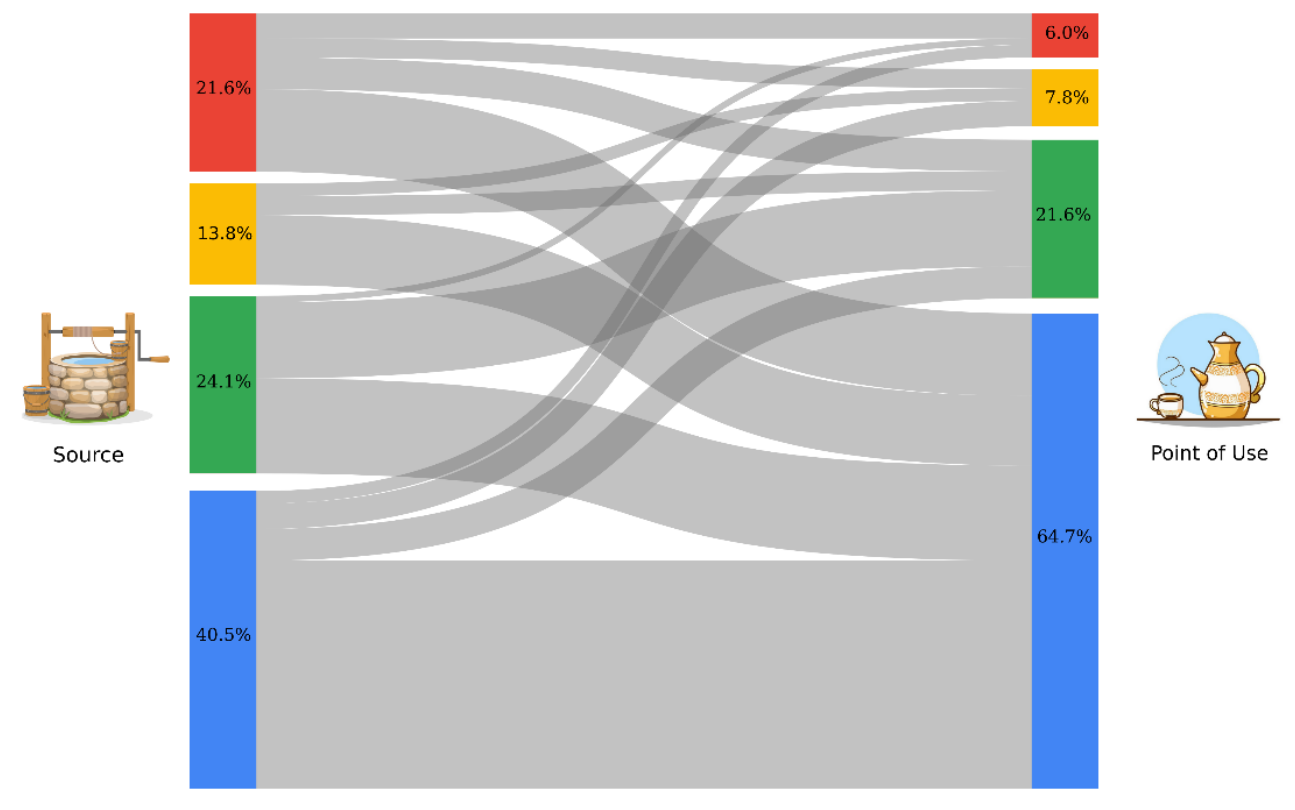




\begin{tabular}{|c|c|c|c|c|}
\hline Risk level & Low & Medium & High & Very High \\
\hline E. coli $($ MPN/100 ml) & $<1$ & $1-10$ & $11-100$ & $>100$ \\
\hline
\end{tabular}

Fig. 1. Sankey Diagram of Water Quality Change for Both Cities $(\mathrm{N}=116)$

Spearman's rank correlation test for various water storage containers E. coli contamination showed no statistically significant relationship (Spearman's $\rho=-0,06$; $\mathrm{P}=0.43$ ). This was consistent with previous study in Bekasi which found no correlation between water storage practices and E. coli contamination in drinking water [19]. Other possible recontamination source could be attributed to drinking cup, where previous studies reported 33\% pollution with E. coli [13]. E. coli was detected in 34\% of cup-acquired samples, compared to $24 \%$ that were acquired directly from the container. Furthermore, Wilcoxon signed-rank test with $95 \%$ confidence level was not able to indicate any significant $E$. coli contamination difference between cup-acquired and container-acquired samples $(\mathrm{P}=0.32)$. Moreover, Spearman also showed no correlation between cup and E. coli contamination (Spearman's $\rho=0,07 ; \mathrm{P}=0.32$ ).

\section{Conclusion}

Based on results and discussion, boiling treatment method in Bekasi and Metro demonstrated an improvement in water quality, however, failed to completely eliminate the microbial risk with only a $\log$ reduction of 0.53 (95\% CI: $0.29-0.79$ ), which corresponds to a $70.5 \%$ decline in E. coli. A statistically significant difference between presence/absence of $E$. coli in source and boiled water $(\mathrm{P}<0.01)$ was observed, confirming some degree of contamination reduction by boiling. Furthermore, water quality change analysis also revealed an improved risk category in $46 \%$ samples after treatment, further assuring the effectiveness of boiling in peri-urban settings. However, in $11 \%$ of cases, water quality deteriorated between source and point of use. This finding may be indicative of inadequate boiling processes or possible recontamination while water is stored. However, the study observed no statistically significant correlation between type of water storage vessel and presence/absence of $E$. coli. Future researches is needed to understand the mechanisms that result in faecal contamination at source and point of use, and also to better pinpoint why boiling practices in some households are inadequate.

This research received funding from Water for Woman, with the support of Australian Government Department of Foreign Affairs and Trade (number WRA1: 1004). The conference funding was received from PTUPT, with the support of Indonesian Ministry of Research and Technology/National Research and Innovation Agency (number NKB-278/UN2.RST/HKP.05.00/2021) and from a collaborative PPKI program from the Indonesian World Class University Research Scheme. We also thank Professor Juliet Willets and Franziska Genter from University of Technology Sydney, Angela Harris from North Carolina State University, and Gita Lestari Putri from Universitas Indonesia for sharing their extensive knowledge and comments on the research findings.

\section{References}

1. WHO, Guidelines for Drinking-Water Quality, 4th ed. (2011)

2. Bappenas, Roadmap of SDGs Indonesia: A Highlight (2020)

3. BPS, Statistik Kesejahteraan Rakyat 2019 (2019)

4. Bappenas, Narasi RPJMN IV 2020-2024 (2019)

5. H. Gusril, Jurnal Geografi 8, 190 (2016) 
6. W. Torres-López, I. Restrepo-Tarquino, C. Patterson, J. Gowing, and I. Dominguez Rivera, I\&U 20, (2015)

7. ADB, Indonesia Country Water Assessment (ASIAN DEVELOPMENT BANK, Place of Publication Not Identified, 2016)

8. S. Aminah and S. Wahyuni, Jurnal Analis Kesehatan 7, 698 (2018)

9. S. Maysarah, G. L. Putri, M. A. Pratama, F. Zulkarnain, J. Willetts, T. Foster, F.

Genter, A. Harris, and C. R. Priadi, IOP Conf. Ser.: Earth Environ. Sci. 566, 012008 (2020)

10. G. Rosa, L. Miller, and T. Clasen, Am. J. Trop. Med. Hyg. 82, 473 (2010)

11. S. V. Sodha, M. Menon, K. Trivedi, A. Ati, M. E. Figueroa, R. Ainslie, K.

Wannemuehler, and R. Quick, J Water Health 9, 577 (2011)

12. S. K. Gupta, A. Suantio, A. Gray, E. Widyastuti, N. Jain, R. Rolos, R. M. Hoekstra, and R. Quick, Am. J. Trop. Med. Hyg. 76, 1158 (2007)

13. S. Rufener, D. Mäusezahl, H.-J. Mosler, and R. Weingartner, J Health Popul Nutr 28, 34 (2010)

14. R. Bain, R. Cronk, J. Wright, H. Yang, T. Slaymaker, and J. Bartram, PLoS Med 11, e1001644 (2014)

15. T. R. Desmarais, H. M. Solo-Gabriele, and C. J. Palmer, Appl Environ Microbiol 68, 1165 (2002)

16. T. F. Clasen and A. Bastable, J Water Health 1, 109 (2003)

17. J. Wright, S. Gundry, and R. Conroy, Trop Med Int Health 9, 106 (2004)

18. S. W. Gundry, J. A. Wright, R. Conroy, M. Du Preez, B. Genthe, S. Moyo, C. Mutisi, J. Ndamba, and N. Potgieter, Water Practice and Technology 1, (2006)

19. I. Imtiyaz, G. L. Putri, D. M. Hartono, F. Zulkarnain, and C. R. Priadi, IOP Conf.

Ser.: Earth Environ. Sci. 633, 012016 (2021) 